\title{
Functional Movement Screen Task Scores and Joint Range-of-motion: A Construct Validity Study
}

\section{(ㄷ) (후) $€$}

\author{
Authors \\ Cesar A. Hincapié1, ${ }^{\mathbb{D}}$, George A. Tomlinson ${ }^{3}$, Malinda Hapuarachchi ${ }^{4}$, Tatjana Stankovic ${ }^{4}$, Steven Hirsch ${ }^{4}$, \\ Danielle Carnegie ${ }^{4}$, Doug Richards ${ }^{4}$, David Frost ${ }^{4}$, Tyson A.C. Beach 5
}

\section{Affiliations}

1 Department of Chiropractic Medicine, Balgrist University Hospital, Zurich, Switzerland

2 Epidemiology, Biostatistics and Prevention Institute (EBPI), University of Zurich, Zurich, Switzerland

3 Dalla Lana School of Public Health, University of Toronto Department of Medicine, Toronto, Canada

4 Faculty of Kinesiology \& Physical Education, University of Toronto, Toronto, Canada

5 Department of Kinesiology \& Health Sciences, University of Waterloo, Waterloo, Canada

Key words

construct validity, functional movement screen, measurement, mobility, range-of-motion, stability

accepted 22.11.2021

published online $\quad 29.11 .2021$

Bibliography

Int J Sports Med 2022; 43: 648-656

DOI 10.1055/a-1708-9735

ISSN $\quad 0172-4622$

(C) 2021. The Author(s).

This is an open access article published by Thieme under the terms of the Creative Commons Attribution-NonDerivative-NonCommercial-License, permitting copying and reproduction so long as the original work is given appropriate credit. Contents may not be used for commecial purposes, or adapted, remixed, transformed or built upon. (https://creativecommons. org/licenses/by-nc-nd/4.0/)

Georg Thieme Verlag KG, Rüdigerstraße 14,

70469 Stuttgart, Germany

\section{Correspondence}

Dr. Cesar A Hincapié

Balgrist University Hospital

Department of Chiropractic Medicine

Forchstrasse 340

8008 Zurich

Switzerland

Tel.: + 41/44/386 5729

cesar.hincapie@uzh.ch

丹 Supplementary Material is available under

https://doi.org/10.1055/a-1708-9735

\begin{abstract}
Little is known about the construct validity of the Functional Movement Screen (FMS). We aimed to assess associations between FMS task scores and measures of maximum joint rangeof-motion (ROM) among university varsity student-athletes from 4 sports (volleyball, basketball, ice hockey, and soccer). Athletes performed FMS tasks and had their maximum ankle, hip and shoulder ROM measured. Multivariable linear regression was used to estimate associations between FMS task scores and ROM measurements. 101 university student-athletes were recruited ( $52 \mathrm{~W} / 49 \mathrm{M}$; mean age $20.4 \pm 1.9$ years). In general, athletes with higher FMS task scores had greater ROM compared to those with lower task scores. For example, athletes who scored 2 on the FMS squat task had $4^{\circ}(95 \% \mathrm{Cl}$, $1^{\circ}$ to $7^{\circ}$ ) more uni-articular ankle dorsiflexion ROM compared with those who scored 1 , while those who scored 3 on the FMS squat task had $10^{\circ}\left(4^{\circ}\right.$ to $\left.17^{\circ}\right)$ more uni-articular ankle dorsiflexion ROM compared with those who scored 1. Large variation in ROM measurements was observed. In sum, substantial overlap in joint ROM between groups of athletes with different FMS task scores weakens the construct validity of the FMS as an indicator of specific joint ROM.
\end{abstract}




\section{Highlights}

- There was substantial overlap in joint ROM measurements between groups of athletes with different FMS task scores.

- FMS task scores should not be interpreted as direct evidence that joint ROM deficits exist.

- Using FMS scores to individualize exercise is not recommended.

- Functional movement screening is an intriguing concept, but its validity remains uncertain.

\section{Introduction}

The Functional Movement Screen (FMS) is promoted as a tool to identify painful and dysfunctional movement patterns. Some preliminary studies have found associations between FMS scores and measures of pain and musculoskeletal injuries in some athletic and occupational populations [1]. However, the underlying nature of the relationship between FMS scores and health or functional status is unknown because little is known about the construct validity of the FMS [2].

Without understanding what is measured by the FMS, it is difficult to know if or how it should be used to design interventions. Nonetheless, interventions have been recommended in the literature based on FMS task scores [3-5], under the assumption that failure to perform FMS tasks in a standard way is indicative of joint mobility and stability deficits $[6,7]$. Although it seems biologically plausible that such deficits should influence FMS task performance, there is very limited evidence that the FMS is a valid instrument to measure joint mobility and stability. Performance on one of its seven component tasks - the deep squat - appears constrained by hip and ankle joint range-of-motion (ROM) capacity [8-12], and composite FMS scores (i. e., sum of all component task scores) are generally higher in performers who have the greatest ankle dorsiflexion ROM [9]. However, it cannot be assumed that joint mobility status, as a hypothetical construct, is accurately characterized by composite scores across all FMS tasks $[13,14]$. In fact, it has been shown that FMS task scores are affected by other underlying processes or constructs unrelated to joint mobility and stability (e.g., performers' knowledge of grading criteria [15]). Before using the FMS to predict injury or prescribe exercise, further evaluation of its validity and measurement properties is needed.

Our objective was to assess the construct validity of the FMS by estimating associations between FMS task scores and joint ROM measures among varsity student-athletes.

\section{Materials and Methods}

\section{Study design and hypotheses}

This was a construct validity study guided by the COSMIN checklist (COnsensus-based Standards for the selection of health Measurement INstruments) [16] for assessing the methodological quality of studies on construct validity (hypotheses testing) measurement properties. We examined two pre-specified hypotheses: (1) On FMS tasks that demand large body segment and joint angular displacements (i. e., deep squat, hurdle step, in-line lunge, active straightleg raise, and shoulder mobility), athletes with lower FMS task scores would have lower joint ROM measures than would athletes with higher task scores; (2) On FMS tasks with minimal ROM requirements (e.g., trunk stability push-up and rotary stability), ROM measures would be unclearly related to FMS task scores.

\section{Participants}

We invited men and women's teams of four university intercollegiate sports (volleyball, basketball, ice hockey, and soccer) at a single university between January 2014 and February 2014 to participate in this study. Eligible were all men and non-pregnant women student-athletes from the above varsity sports rosters available to participate in ROM measurements and FMS testing in a university sports medicine clinical setting. Intercollegiate varsity sport is considered a high-performance sport level in Canada. Depending on the structure for the specific sport, athletes participating at the varsity sport level are on a pathway for national and international competition or have experience playing semi-professionally. Many of these athletes would also have experience within the provincial and national sport development systems.

Athletes were eligible to participate irrespective of previous injury and pre-existing musculoskeletal issues if they were cleared to participate in all team related activities (i. e., practices, strength and conditioning, games, etc.). For our primary analysis, we excluded participants that expressed painful movement with a specific FMS task (i. e., an FMS score of zero) because pain is known to alter movement independently of joint ROM capacity.

\section{General procedures}

FMS and ROM data were collected from an athlete on the same day. Order of exposure to the ROM and FMS data collection sessions was assigned in a balanced and pragmatic manner due to scheduling constraints across athletes, therapists, and teams. A minimum of 10 minutes of passive recovery was provided between ROM and FMS data collections. The observer responsible for scoring FMS movement tasks was blinded to the ROM data for the participants, and vice-versa, the therapists responsible for collecting ROM measurements were blinded to the FMS scores. These data were gathered and filed separately and the participants and assessors in both data collection phases were not aware of the scores and measurements of the other assessment.

\section{FMS data collection}

A single member of the research team, with over six months of experience and training in using the FMS, administered the FMS in accordance with standard protocols $[6,7]$ and conducted all FMS scoring. FMS scores can be reliably assigned by raters with a range of background experiences and training [2]. Participants were blind to the scoring criteria as they were performing the FMS tasks. They were provided with only the standard instructions. They were also blinded to their FMS scores throughout the entire data collection procedures for the study.

Synchronized video recordings (Dartfish, Fribourg, Switzerland) were made from both frontal and sagittal plane perspectives to permit FMS tasks to be graded offline. Athletes performed the deep squat (squat), hurdle step (hurdle), in-line lunge (lunge), and rotary stability (rotary) tasks twice while facing the frontal camera and twice while facing away (i. e., four repetitions of the squat, hurdle, lunge, and rotary tasks were performed in total, with the frontal 
camera capturing anterior and posterior views). The shoulder mobility (shoulder) task was performed three times while athletes faced away from the frontal camera (i. e., posterior view). Athletes performed the active straight leg raise (slr) task three times per side with the top of their head facing away from the frontal camera (i. e., inferior/caudal view). The trunk stability push-up (pushup) task was performed twice with the plantar surface of the feet facing the frontal camera (i. e., inferior/caudal view), and twice while facing away (i.e., superior/cranial view). Each pain-clearing test was recorded while facing the frontal camera (i. e., posterior view), and the left side of all bilateral tasks was performed first. Raw video recordings of the FMS tasks were cropped, compressed, and coded by research assistants before creating synchronized splitscreen (frontal and sagittal plane view) output files (Dartfish, Fribourg, Switzerland).

Standard criteria $[6,7]$ were used to grade FMS tasks offline using a four-point ordinal scale, with possible scores of $0,1,2$ and 3. The researcher who administered and graded the FMS observed all the video recordings for each movement task and assigned the specific FMS task score based on visual observation of video recordings. This same procedure was followed for each movement task across each subject. For the bilateral tasks (hurdle, lunge, shoulder, slr, rotatory), the left and right sides were evaluated separately using the same procedure as above. To obtain the composite score for the bilateral tasks, the minimum value between the left and right side was used as per the scoring criteria of the FMS.

\section{Range-of-motion data collection}

Passive ankle dorsiflexion, hip extension, hip flexion, and shoulder flexion ROM availability were measured bilaterally both with and without imposing multi-articular restraints on motion, for a total of eight ROM measurements (see Appendix Fig A1 for full details on joint ROM measurements). All ROM measurements were made on each athlete in the same order, with left side measured before the right, and repeated twice. Two trained research assistants helped with body positioning and data recording, while 6 licensed therapists made measurements using a manual goniometer. In preliminary work, where intraclass correlation coefficients (ICCs) were calculated for the ROM measures used in the current study [17], the inter-rater reliability of these ROM measurements ranged between good (ICC $=0.61)$ and excellent $(I C C=0.86)$, with the exception of multi-articular ankle dorsiflexion measurement, which was fair $(I C C=0.53)$. Repeated ROM measurements were averaged for each side individually; the lower of left- and right-side average values was used to represent the ROM available at each joint.

\section{Statistical analysis}

Descriptive summaries of participants' characteristics and FMS task scores were provided for the study population and by sex subgroups. As our interest was in examining all eligible participants of the four targeted sports, we did not calculate a pre-study sample size. Using multivariable linear regression analysis, we estimated the associations between FMS task scores (as a 3-level categorical factor) and ROM measurements (as continuous term), with ROM measurements as the outcome of interest and FMS task scores as the main explanatory variable, while adjusting for age, sex, and body mass index (BMI) as potential confounders. Age and BMI were included as continuous terms and sex as a binary factor in every model. Every combination of FMS task scores and joint ROM measurements were modelled separately to investigate whether relationships were present when hypothesised as plausible and not present when hypothesised as implausible. Observations with an FMS score of zero - assigned when a participant expresses painful movement - were excluded from the regression analyses because pain is known to alter movement independently of joint ROM [18]. The distributions of ROM measurements were then plotted for each of the FMS tasks by the task scores (from 1 to 3 ; higher scores indicate better performance). For the 3-level FMS variable, we first examined whether the three adjusted mean ROM values were all equal; this hypothesis has a single $p$ value, which we called the overall $p$-value. Then, we calculated $p$ values for specific pairs of comparisons of adjusted mean ROM values between different FMS levels (e. g., 2 vs. 1, 3 vs. 1, 3 vs. 2). As a visual aid to the identification of the most notable associations, where the overall $p$-values from the regressions were less than 0.1 , the individual plots were highlighted in colour. Given the exploratory nature of our analysis, we did not adjust for multiple comparisons - this is preferable as it leads to fewer errors of interpretation [19]. All $p$-values and $95 \%$ confidence intervals (Cls) were two-sided, and analyses were performed in R version 3.6.0 [20].

\section{Ethical approval and patient and public involvement}

Our study was conducted in accordance with recognised ethical standards in sport and exercise science research [21]. All participants gave written informed consent. The study was approved by the independent Office of Research Ethics at the University of Toronto. Patients or the public were not involved in the design, conduct, reporting, or dissemination plans of this study.

\section{Results}

\section{Participant characteristics}

We recruited 101 university varsity student-athletes (out of 156 eligible; $64 \%$ participation): 26 from volleyball ( $84 \%$ participation), 21 from basketball (68\% participation), 32 from ice hockey (64\% participation), and 22 from soccer (48\% participation) ( $>$ Table 1 ). There were 52 female participants (mean age 19.9 years) and 49

- Table 1 Characteristics of study population.

\begin{tabular}{|l|l|l|l|}
\hline Characteristic & $\begin{array}{l}\text { All } \\
(\mathbf{N}=\mathbf{1 0 1})\end{array}$ & $\begin{array}{l}\text { Women } \\
(\mathbf{n = 5 2})\end{array}$ & $\begin{array}{l}\text { Men } \\
\mathbf{( N = 4 9 )}\end{array}$ \\
\hline Age (y) - mean (SD) & $20.4(1.9)$ & $19.9(1.9)$ & $20.8(1.9)$ \\
\hline $\begin{array}{l}\text { Height (cm) } \\
\text { mean (SD) }\end{array}$ & $177.2(10.2)$ & $170.3(7.4)$ & $184.5(7.1)$ \\
\hline Mass (kg) - mean (SD) & $74.8(12.6)$ & $66.2(8.0)$ & $83.9(10.1)$ \\
\hline $\begin{array}{l}\text { BMI (kg/m²)- } \\
\text { mean (SD) }\end{array}$ & $23.7(2.1)$ & $22.8(2.0)$ & $24.6(2.0)$ \\
\hline Sport - N (\%) & & & $12(24.5)$ \\
\hline Hockey & $32(31.7)$ & $20(38.5)$ & $12(24.5)$ \\
\hline Volleyball & $26(25.7)$ & $14(26.9)$ & $14(28.6)$ \\
\hline Soccer & $22(21.8)$ & $8(15.4)$ & $11(22.4)$ \\
\hline Basketball & $21(20.8)$ & $10(19.2)$ & 12 \\
\hline
\end{tabular}


male participants (mean age 20.8 years). With respect to the sport training and competition experience of the study population, the four varsity teams included in this study typically trained 3-5 times per week, had 2-3 strength and conditioning sessions per week, and 1-2 games per week for those sports in their competitive seasons. Soccer was "out-of-season" and did not have any intercollegiate games during the data collection period.

\section{FMS scores}

The mean total FMS score (out of 21) for the whole group was 13.1 $(95 \% \mathrm{Cl}, 12.7$ to 13.5$)$. A total of 25 participants were assigned at least one FMS task score of 0 , yielding an estimated point prevalence of painful movement elicited by the FMS in our study population of $25 \%$ ( $95 \% \mathrm{Cl}, 17$ to $35 \%$ ). - Table 2 details the frequency distribution of FMS task scores for the seven FMS tasks. Of note, the FMS hurdle and rotary tasks were poor differentiating tasks - no student-athlete in our study was assigned a score of 3 for the rotary task, and no participant scored 1 on the hurdle task ( $\vee$ Fig. 1 and > Table 2).

\section{Construct validity outcomes - FMS scores and ROM availability}

There were several notable (i. e., $p<0.1$ ) differences in ankle, hip, and shoulder joint ROM measures between athletes who scored 1 , 2, or 3 on FMS tasks ( $>$ Fig. 1, $>$ Table 3 and Appendix Table A1). Squat and lunge task scores were positively associated with ankle dorsiflexion ROM; lunge task scores positively associated with hip extension ROM; and squat and shoulder task scores positively associated with shoulder flexion ROM. There was considerable variation in individual ROM measures within FMS task score levels of 1 , 2 or 3 ( $\vee$ Fig. 1). For athletes who scored 1 on the FMS squat task, for example, the range of uni-articular ankle dorsiflexion ROM measurements was more than 30 -degrees ( $>$ Fig. 1). There was overlap in joint ROM availability between groups of athletes with different FMS task scores.

We hypothesized that on FMS tasks with large ROM requirements (squat, hurdle, lunge, slr and shoulder tasks) athletes scoring higher on the FMS task would have greater ROM (Hyp1). Athletes rated as having higher FMS squat scores had greater uni- and multi-articular ankle dorsiflexion ROM than did athletes who scored lower on the squat ( $\triangleright$ Fig. 1, $\triangleright$ Table 3 and Appendix Table A1). For instance, athletes who scored 2 on the FMS squat task had $4^{\circ}$ ( $95 \% \mathrm{Cl}, 1^{\circ}$ to $7^{\circ} ; p=0.009$ ) more uni-articular ankle dorsiflexion ROM compared with those who scored 1 , while those who scored 3 on the FMS squat task had $10^{\circ}\left(4^{\circ}\right.$ to $\left.17^{\circ} ; p=0.003\right)$ more uniarticular ankle dorsiflexion ROM compared with those who scored 1. Although not statistically significant at an alpha level of 0.05 , there was a tendency for athletes with higher FMS squat scores to have greater multi-articular ankle dorsiflexion ROM than those with lower squat scores (FMS score 2 vs $1:+2^{\circ}\left[-1^{\circ}\right.$ to $\left.+6^{\circ}\right]$ multi-articular ankle dorsiflexion ROM, $p=0.144$; FMS score 3 vs $1:+7^{\circ}\left[0^{\circ}\right.$ to $\left.+14^{\circ}\right], p=0.051 ;$ FMS score 3 vs $2:+5^{\circ}\left[-3^{\circ}\right.$ to $\left.+12^{\circ}\right], p=0.202$; - Table 3).

Higher FMS lunge task scores were associated with greater ankle dorsiflexion ROM, both uni- and multi-articularly, and greater uniarticular and multi-articular hip extension ROM ( $\triangleright$ Table 3). Both uni-articular and multi-articular shoulder ROM was greater in ath-
- Table 2 Summary of FMS Scores.

\begin{tabular}{|c|c|c|c|}
\hline FMS score & $\begin{array}{l}\text { All } \\
(N=101)\end{array}$ & $\begin{array}{l}\text { Women } \\
(n=52)\end{array}$ & $\begin{array}{l}\text { Men } \\
(N=49)\end{array}$ \\
\hline $\begin{array}{l}\text { Total score out of } \\
21-\text { mean }(95 \% \mathrm{Cl})\end{array}$ & $\begin{array}{l}13.1 \\
(12.7-13.5)\end{array}$ & $\begin{array}{l}13.2 \\
(12.7-13.7)\end{array}$ & $\begin{array}{l}13.0 \\
(12.4-13.6)\end{array}$ \\
\hline \multicolumn{4}{|l|}{ Squat $-N(\%)$} \\
\hline 0 & $1(1.0)$ & 0 & $1(2.0)$ \\
\hline 1 & $57(56.4)$ & $28(53.8)$ & $29(59.2)$ \\
\hline 2 & $38(37.6)$ & $23(44.2)$ & $15(30.6)$ \\
\hline 3 & $5(5.0)$ & $1(1.9)$ & $4(8.2)$ \\
\hline \multicolumn{4}{|l|}{ Hurdle - N (\%) } \\
\hline 0 & 0 & 0 & 0 \\
\hline 1 & 0 & 0 & 0 \\
\hline 2 & $87(86.1)$ & $43(82.7)$ & $44(89.8)$ \\
\hline 3 & $14(13.9)$ & $9(17.3)$ & $5(10.2)$ \\
\hline \multicolumn{4}{|l|}{ Lunge - N (\%) } \\
\hline 0 & $3(3.0)$ & $1(1.9)$ & $2(4.1)$ \\
\hline 1 & $4(4.0)$ & 0 & $4(8.2)$ \\
\hline 2 & $84(83.2)$ & $48(92.3)$ & $36(73.5)$ \\
\hline 3 & $10(9.9)$ & $3(5.8)$ & $7(14.3)$ \\
\hline \multicolumn{4}{|l|}{ Shoulder - N (\%) } \\
\hline 0 & $14(13.9)$ & $5(9.6)$ & $9(18.4)$ \\
\hline 1 & $6(5.9)$ & $2(3.8)$ & $4(8.2)$ \\
\hline 2 & $42(41.6)$ & $23(44.2)$ & $19(38.8)$ \\
\hline 3 & $39(38.6)$ & $22(42.3)$ & $17(34.7)$ \\
\hline \multicolumn{4}{|l|}{$S L R-N(\%)$} \\
\hline 0 & 0 & 0 & 0 \\
\hline 1 & $38(37.6)$ & $19(36.5)$ & $19(38.8)$ \\
\hline 2 & $50(49.5)$ & $22(42.3)$ & $28(57.1)$ \\
\hline 3 & $13(12.9)$ & $11(21.2)$ & $2(4.1)$ \\
\hline \multicolumn{4}{|l|}{ Push-up - N (\%) } \\
\hline 0 & $9(8.9)$ & $3(5.8)$ & $6(12.2)$ \\
\hline 1 & $38(37.6)$ & $32(61.5)$ & $6(12.2)$ \\
\hline 2 & $19(18.8)$ & $3(5.8)$ & $16(32.7)$ \\
\hline 3 & $35(34.7)$ & $14(26.9)$ & $21(42.9)$ \\
\hline \multicolumn{4}{|l|}{ Rotary - N (\%) } \\
\hline 0 & $3(3.0)$ & $1(1.9)$ & $2(4.1)$ \\
\hline 1 & $6(5.9)$ & $3(5.8)$ & $3(6.1)$ \\
\hline 2 & $92(91.1)$ & $48(92.3)$ & $44(89.8)$ \\
\hline 3 & 0 & 0 & 0 \\
\hline
\end{tabular}

letes with higher FMS shoulder task scores compared to those with lower FMS shoulder scores. Athletes who scored highest on the FMS slr task had the greatest multi-articular hip flexion ROM (FMS score 2 vs $1:+9^{\circ}\left[+4^{\circ}\right.$ to $\left.+14^{\circ}\right], p<0.001$; FMS score 3 vs $1:+17^{\circ}\left[+9^{\circ}\right.$ to $\left.+24^{\circ}\right], p<0.001$; FMS score 3 vs $2:+8^{\circ}\left[+1^{\circ}\right.$ to $\left.+15^{\circ}\right], p=0.032$; - Table 3). Although there were several expected relationships between FMS task scores and joint ROM, there was still substantial unexplained variability in ROM, with the largest $R^{2}$ in any of our models being 0.33 for the FMS slr task and multi-articular hip flexion ROM.

We also hypothesized that on FMS tasks with minimal ROM requirements (pushup and rotary tasks), ROM would be unclearly re- 


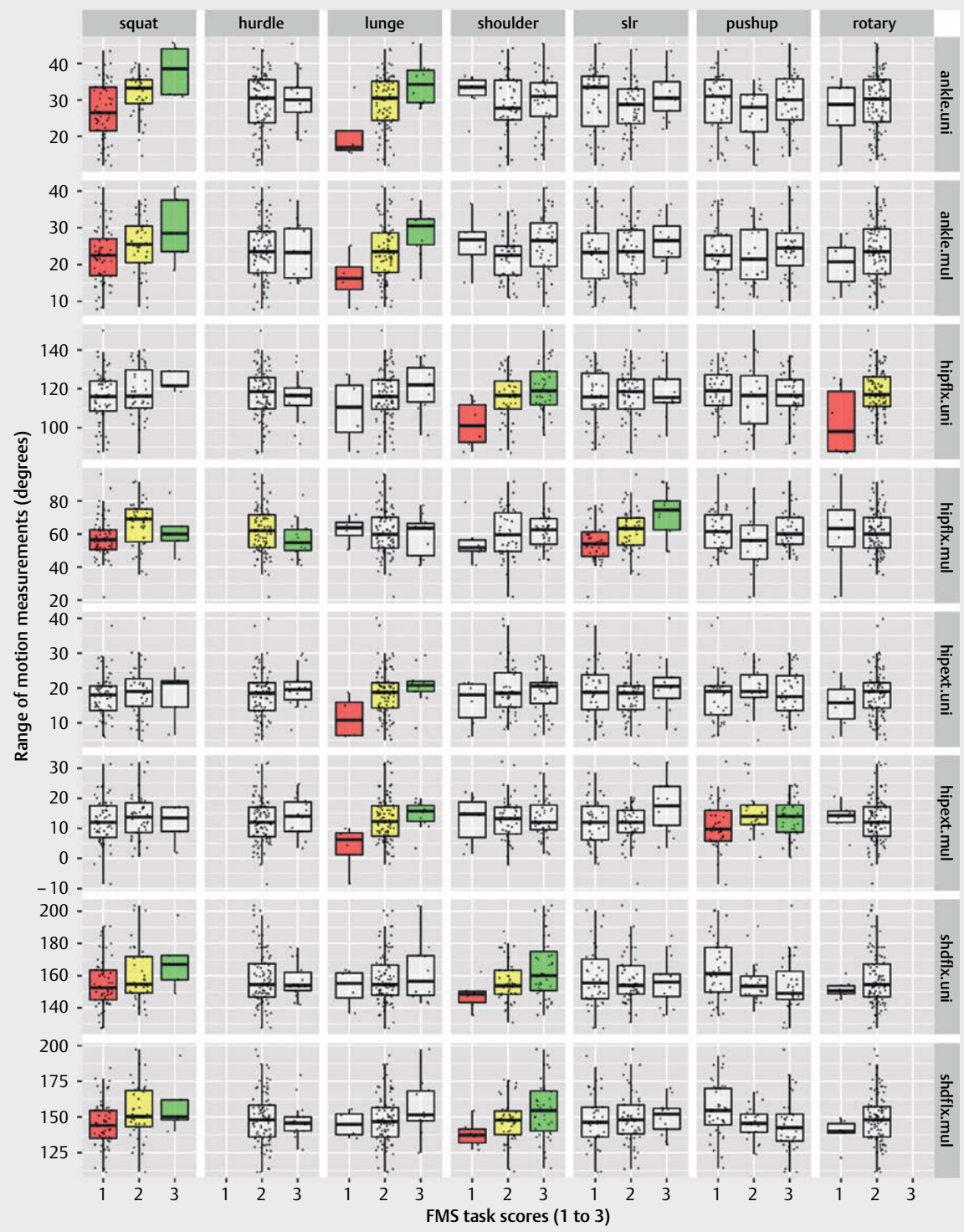

- Fig. 1 Range-of-motion measurements by FMS task scores in university intercollegiate student-athletes (higher scores indicate better task performance and coloured boxplots indicate notable relationships with overall $p<0.1$ ).

lated to FMS task scores (Hyp2). This was the case for most FMS task scores and ROM comparisons for the pushup and rotary FMS tasks ( $\vee$ Fig. 1, $\triangleright$ Table 3 and Appendix Table A1). Unexpectedly, we observed that athletes rated as 3 for the FMS shoulder task had greater uni-articular hip flexion ROM than did athletes rated at 1 for the shoulder task (overall $p=0.007$ ). We also observed an unexpected positive association between the FMS pushup scores and multi-articular hip extension ROM (overall $p=0.003$ ).

\section{Discussion}

To date, there is limited evidence to suggest that the FMS is a valid instrument indicative of joint mobility and stability deficits. Consistent with some of our pre-specified hypotheses, we found a few differences in joint ROM among student-athletes rated as scoring
1, 2, or 3 on FMS tasks. However, not all ROM measurements differed between athletes with different FMS task scores, and associations between FMS scores and ROM were not always in same direction. At the level of individual participants, we found substantial overlap in joint ROM between groups of athletes with different FMS task scores.

\section{Key findings and implications}

We found higher FMS squat and lunge task scores to be generally associated with more ankle dorsiflexion ROM, which is consistent with prior research for the squat task $[9,10,12]$ but not for the lunge task [9]. Athletes with the most hip extension ROM tended to be those with the highest lunge scores in the current study - this differs from previous findings [8, 22]. Shoulder flexion ROM was generally greater in those athletes with higher shoulder and squat 
- Table 3 Multivariable linear regression analysis results for notable associations (overall $p<0.1$ ) between FMS task scores (levels 1 to 3 ) and range-ofmotion measurements in university student-athletes.

\begin{tabular}{|c|c|c|c|c|c|}
\hline Joint ROM ${ }^{*}$ & FMS task & FMS score comparison & $\begin{array}{l}\text { Mean ROM difference in } \\
\text { degrees }(95 \% \mathrm{Cl})\end{array}$ & $p$ & overall $p$ \\
\hline \multirow[t]{3}{*}{ ankle.uni } & \multirow[t]{3}{*}{ squat } & $2 \mathrm{v} 1$ & $+4(+1$ to +7$)$ & 0.009 & \multirow[t]{3}{*}{0.002} \\
\hline & & $3 \mathrm{v} 1$ & $+10(+4$ to +17$)$ & 0.003 & \\
\hline & & $3 \mathrm{v} 2$ & $+6(-1$ to +13$)$ & 0.076 & \\
\hline \multirow[t]{3}{*}{ ankle.uni } & \multirow[t]{3}{*}{ lunge } & $2 \mathrm{v} 1$ & $+7(0$ to +15$)$ & 0.060 & \multirow[t]{3}{*}{0.019} \\
\hline & & $3 \mathrm{v} 1$ & $+12(+3$ to +21$)$ & 0.007 & \\
\hline & & $3 \mathrm{v} 2$ & $+5(0$ to +10$)$ & 0.053 & \\
\hline \multirow[t]{3}{*}{ ankle.mul } & \multirow[t]{3}{*}{ squat } & $2 \mathrm{v} 1$ & $+2(-1$ to +6$)$ & 0.144 & \multirow[t]{3}{*}{0.079} \\
\hline & & $3 \mathrm{v} 1$ & $+7(0$ to +14$)$ & 0.051 & \\
\hline & & $3 \mathrm{v} 2$ & $+5(-3$ to +12$)$ & 0.202 & \\
\hline \multirow[t]{3}{*}{ ankle.mul } & \multirow[t]{3}{*}{ lunge } & $2 \mathrm{v} 1$ & $+6(-2$ to +14$)$ & 0.152 & \multirow[t]{3}{*}{0.037} \\
\hline & & $3 \mathrm{v} 1$ & $+11(+2$ to +20$)$ & 0.018 & \\
\hline & & $3 \mathrm{v} 2$ & $+5(0$ to +10$)$ & 0.046 & \\
\hline \multirow[t]{3}{*}{ hipflx.uni } & \multirow[t]{3}{*}{ shoulder } & $2 \mathrm{v} 1$ & $+12(+1$ to +23$)$ & 0.031 & \multirow[t]{3}{*}{0.007} \\
\hline & & $3 \mathrm{v} 1$ & $+17(+6$ to +28$)$ & 0.003 & \\
\hline & & $3 \mathrm{v} 2$ & $+5(-0$ to +10$)$ & 0.072 & \\
\hline hipflx.uni & rotary & $2 \mathrm{v} 1$ & $+15(+5$ to +26$)$ & 0.004 & 0.004 \\
\hline \multirow[t]{3}{*}{ hipflx.mul } & \multirow[t]{3}{*}{ squat } & $2 \mathrm{v} 1$ & $+7(+2$ to +12$)$ & 0.009 & \multirow[t]{3}{*}{0.031} \\
\hline & & $3 \mathrm{v} 1$ & $+4(-7$ to +16$)$ & 0.471 & \\
\hline & & $3 \mathrm{v} 2$ & $-3(-15$ to +9$)$ & 0.633 & \\
\hline hipflx.mul & hurdle & $3 \mathrm{v} 2$ & $-7(-14$ to 0$)$ & 0.066 & 0.066 \\
\hline \multirow[t]{3}{*}{ hipflx.mul } & \multirow[t]{3}{*}{ slr } & $2 \mathrm{v} 1$ & $+9(+4$ to +14$)$ & $<0.001$ & \multirow[t]{3}{*}{$<0.001$} \\
\hline & & $3 \mathrm{v} 1$ & $+17(+9$ to +24$)$ & $<0.001$ & \\
\hline & & $3 \mathrm{v} 2$ & $+8(+1$ to +15$)$ & 0.032 & \\
\hline \multirow[t]{3}{*}{ hipext.uni } & \multirow[t]{3}{*}{ lunge } & $2 \mathrm{v} 1$ & $+6(-1$ to +13$)$ & 0.083 & 0.097 \\
\hline & & $3 v 1$ & $+8(+1$ to +16$)$ & 0.031 & \\
\hline & & $3 \mathrm{v} 2$ & $+2(-2$ to +7$)$ & 0.260 & \\
\hline hipext.mul & lunge & $2 \mathrm{v} 1$ & $+9(+1$ to +16$)$ & 0.028 & 0.060 \\
\hline & & $3 \mathrm{v} 1$ & $+10(+2$ to +19$)$ & 0.021 & \\
\hline & & $3 \mathrm{v} 2$ & $+2(-3$ to +7$)$ & 0.489 & \\
\hline hipext.mul & pushup & $2 \mathrm{v} 1$ & $+8(+4$ to +13$)$ & $<0.001$ & 0.003 \\
\hline & & $3 \mathrm{v} 1$ & $+5(+1$ to +9$)$ & 0.011 & \\
\hline & & $3 \mathrm{v} 2$ & $-3(-7$ to +1$)$ & 0.106 & \\
\hline shdflx.uni & squat & $2 \mathrm{v} 1$ & $+6(-1$ to +13$)$ & 0.0816 & 0.039 \\
\hline & & $3 \mathrm{v} 1$ & $+16(+1$ to +31$)$ & 0.0315 & \\
\hline & & $3 \mathrm{v} 2$ & $+10(-5$ to +25$)$ & 0.178 & \\
\hline shdflx.uni & shoulder & $2 \mathrm{v} 1$ & $+10(-4$ to +23$)$ & 0.165 & 0.009 \\
\hline & & $3 \mathrm{v} 1$ & $+18(+4$ to +32$)$ & 0.0109 & \\
\hline & & $3 \mathrm{v} 2$ & $+8(+2$ to +15$)$ & 0.0167 & \\
\hline shdflx.mul & squat & $2 \mathrm{v} 1$ & $+9(+1$ to +16$)$ & 0.0194 & 0.016 \\
\hline & & $3 \mathrm{v} 1$ & $+17(+1$ to +33$)$ & 0.035 & \\
\hline & & $3 \mathrm{v} 2$ & $+8(-8$ to +25$)$ & 0.301 & \\
\hline shdflx.mul & shoulder & $2 \mathrm{v} 1$ & $+10(-5$ to +25$)$ & 0.192 & 0.038 \\
\hline & & $3 v 1$ & $+17(+2$ to +33$)$ & 0.0278 & \\
\hline & & $3 \mathrm{v} 2$ & $+7(0$ to +15$)$ & 0.0636 & \\
\hline $\begin{array}{l}{ }^{*} \text { ankle.uni is } \\
\text { mul is multi-a } \\
\text { uni-articular s } \\
\text { sex and BMI. }\end{array}$ & $\begin{array}{l}\text { ankle dors } \\
\text { lexion RON } \\
\text { on ROM; s }\end{array}$ & $\begin{array}{l}\text { Inkle.mul is multi-articul } \\
\text { uni-articular hip extensi } \\
\text { Iti-articular shoulder fle }\end{array}$ & $\begin{array}{l}\text { le dorsiflexion ROM; hipfl } \\
\text { M; hipext.mul is multi-art } \\
\text { OM; All multivariable line }\end{array}$ & $\begin{array}{l}\text { ticular } \\
\text { ension R } \\
\text { models }\end{array}$ & $\begin{array}{l}\text { ROM; hipflx } \\
\text { x.uni is } \\
\text { usted for ag }\end{array}$ \\
\hline
\end{tabular}


task scores; however, previous research failed to find relationships between shoulder scores and glenohumeral joint ROM measurements [23]. Our finding that athletes who achieved higher squat and slr task scores typically had greater hip flexion ROM (with multiarticular restraints imposed) also contrasts with prior research. Specifically, it was previously reported that hip flexion ROM measures made with only uni-articular motion restraints imposed were related to squat task scores [8], but we found no such relationship. In fact, the only statistically notable associations we found between FMS task scores and uni-articular hip flexion ROM were for shoulder and rotary tasks. It is reasonable that hip flexion ROM could influence rotary task performance, but its relationship to shoulder scores is likely a statistical anomaly. Finally, we found that athletes who scored lower, compared to higher, on the pushup task had more shoulder flexion ROM, which may imply that ability to stabilize the shoulder complex may be compromised by having more shoulder mobility.

Functional movement screening is an intriguing concept; however, critical evaluation of the concept, constructs and associated measurement properties is warranted and needed. The FMS may be reliable, but its validity is uncertain [2]. Similar conclusions have been drawn about other functional movement screens [24]. As an injury prediction tool, the evidence for the utility of the FMS is equivocal at best [25-28], as are the associations between FMS scores and movement kinematics [29] or function [30, 31]. Furthermore, a convincing argument has been made against using functional movement screens for predicting injury [32]. As a means to identify joint mobility and stability deficits, results of our current and previous studies [15] challenge whether this can be done based solely on visual observation of complex whole-body movements. Movement patterns are inherently variable within and between performers because coordination and control processes are governed by non-linear interactions between personal, task, and environmental constraints [33]. Therefore, visually observed deviations from an assumed "ideal" or "optimal" movement pattern are not - in themselves - evidence of dysfunction. In their book [34], the FMS creators advised against using the FMS for diagnostic purposes, recommending instead the Selective Functional Movement Assessment (SFMA) to identify sources of pain and dysfunction. Ultimately, validated assessments are required to confirm the presence of joint mobility and stability deficits.

Our results - when taken together with previous research - offer partial support for using a subset of FMS task scores as a crude indicator of sagittal plane joint ROM capacity. However, it must be emphasized that the body of evidence is based on data collected from different populations (i. e., athletes, recreationally active young adults, firefighters, and police officers) and involves different active, passive, and active-assisted ROM measurements. Therefore, any inferences made about joint ROM based on FMS task scores should be informed by kinesiological theory, account for equivocal findings across studies, and be confirmed on an individual basis using validated ROM assessments.

\section{Practical advantages}

Our results show that some FMS task scores may be used to screen for potential joint ROM deficits at a group-level. This is beneficial to identify individual athletes from large teams in a time-efficient and cost-effective manner who may be candidates for further assessment. With that said, our data do not support using FMS task scores by themselves to make personalized exercise recommendations. For example, $>$ Figure $\mathbf{1}$ showed that an individual with an FMS squat score of 1 did not necessarily have ankle dorsiflexion ROM limitations, and that an individual with a squat score of 3 was unlikely to have ankle dorsiflexion ROM limitations. More formally, when used as a screen to detect ankle dorsiflexion ROM deficits, the squat had high sensitivity (i. e., low false-negative rate) and low specificity (i. e., high false-positive rate) [10]. Altogether, these findings imply that performance on a subset of FMS tasks may be used to rule out joint ROM restrictions, but should not be used to rule-them-in. To confirm the presence of genuine joint ROM deficits, validated assessments are needed. If such assessments confirm that ROM deficits are present, further evaluation would be required to determine if ROM-constraining factors are potentially modifiable (e. g., soft tissue compliance) or non-modifiable (e.g., bony anatomy) before prescribing corrective exercises.

\section{Methodological limitations}

First, our statistical analyses incorporated the lower average values of unilateral ROM measurements and lower scores of unilateral FMS tasks. This limited our ability to assess direct relationships between specific FMS scores and ROM measures, but was a necessary simplification, given the vast number of statistical tests that would be required to investigate bilateral asymmetries. Second, we used manual goniometry to make passive ROM measurements. Using kinematic recording systems to measure joint ROM may have resulted in more reliable and accurate measurements. However, we carried out preliminary reliability work [17] that supported our use of manual goniometry by experienced therapists for our study purposes. Third, we acknowledge that our ROM measures may not directly and fully represent the notion of "mobility" suggested by FMS proponents, especially given that only relatively small numbers and types of ROM measures were incorporated. When observing whole-body movements like FMS tasks, the joint motion exhibited is constrained by factors other than the amount available (e.g., ability to position and control motion of remote joints, open- vs. closed-chain movements, etc.). This makes it difficult to operationally conceptualize "mobility", which is why we used a deducible component of mobility in our study - amount of joint ROM available with and without multi-articular motion restraints imposed.

\section{Conclusion}

Our findings generally support using FMS squat task scores to screen for ankle dorsiflexion, and hip and shoulder flexion ROM limitations. Support was also found for using the slr and shoulder tasks to screen for potential hip and shoulder flexion ROM limitations, respectively. However, low FMS task scores should not be interpreted as evidence that joint ROM deficits exist - the FMS was not designed for this purpose. Rather, FMS task scores may be used to screen for potential joint ROM deficits before using a validated assessment for diagnostic and intervention purposes. 


\section{Contributorship}

All authors made a significant contribution to the work reported, whether that is in the conception, study design, execution, acquisition of data, analysis, and interpretation, or in all these areas; took part in drafting, revising or critically reviewing the article; gave final approval of the version to be published; have agreed on the journal to which the article has been submitted; and agree to be accountable for all aspects of the work.

\section{Data Sharing Statement}

The datasets used and analysed during the current study are available from the corresponding author on reasonable request.

\section{Ethical Approval Information}

All participants gave written informed consent. The study was approved by the independent Office of Research Ethics at the University of Toronto.

\section{Acknowledgements}

We would like to thank Ms. Andrea Prieur and Mr. Adrian Lightowler for their assistance with coordinating data collection sessions. We thank all therapists from the David L. Maclntosh Sports Medicine Clinic involved in collecting joint range-of-motion measurements, and Varsity Blues coaches and athletes for their participation.

Competing Interests We wish to confirm that there are no known conflicts of interest associated with this publication and there has been no significant financial support for this work that could have influenced its outcome.

\section{Conflict of Interest}

The authors declare that they have no conflict of interest

\section{References}

[1] Bunn PDS, Rodrigues AI, Bezerra da Silva E. The association between the functional movement screen outcome and the incidence of musculoskeletal injuries: A systematic review with meta-analysis. Phys Ther Sport 2019; 35: 146-158

[2] Bonazza NA, Smuin D, Onks CA et al. Reliability, validity, and injury predictive value of the functional movement screen: a systematic review and meta-analysis. Am J Sports Med 2017; 45: 725-732

[3] Bodden JG, Needham RA, Chockalingam N. The effect of an intervention program on functional movement screen test scores in mixed martial arts athletes. J Strength Cond Res 2015; 29: 219-225

[4] Campa F, Spiga F, Toselli S. The effect of a 20-week corrective exercise program on functional movement patterns in youth elite male soccer players. J Sport Rehabil 2019; 28: 746-751

[5] Stanek JM, Dodd D], Kelly AR et al. Active duty firefighters can improve functional movement screen (FMS) scores following an 8-week individualized client workout program. Work 2017; 56: 213-220
[6] Cook G, Burton L, Hoogenboom B] et al. Functional movement screening: the use of fundamental movements as an assessment of function - Part 1. Int J Sports Phys Ther 2014; 9: 396-409

[7] Cook G, Burton L, Hoogenboom B] et al. Functional movement screening: the use of fundamental movements as an assessment of function - Part 2. Int J Sports Phys Ther 2014; 9: 549-563

[8] Frost D, Andersen J, Lam T et al. The relationship between general measures of fitness, passive range of motion and whole-body movement quality. Ergonomics 2013; 56: 637-649

[9] Chimera NJ, Knoeller S, Cooper R et al. Prediction of functional movement screen performance from lower extremity range of motion and core tests. Int J Sports Phys Ther 2017; 12: 173-181

[10] Rabin A, Kozol Z. Utility of the overhead squat and forward arm squat in screening for limited ankle dorsiflexion. J Strength Cond Res 2017; 31: 1251-1258

[11] Oleksiak J, Sobianek A, Janiszewski M. The effect of corrective exercises on the range of motion of the hip joints and the result obtained in the deep squat of FMS test. Cent Eur J Sport Sci Med 2019; 26: 31-40

[12] Gomes J, Neto T, Vaz JR et al. Is there a relationship between back squat depth, ankle flexibility, and Achilles tendon stiffness? Sports Biomech 2020. Online ahead of print. doi: 10.1080/14763141.2019.1690569

[13] Kelleher LK, Beach TAC, Frost DM et al. Factor structure, stability, and congruence in the functional movement screen. Meas Phys Educ Exerc Sci 2018; 22: 109-115

[14] Wright MD, Chesterton P. Functional movement screen total score does not present a gestalt measure of movement quality in youth athletes. J Sports Sci 2019; 37: 1393-1402

[15] Frost DM, Beach TAC, Callaghan JP et al. FMS scores change with performers' knowledge of the grading criteria - Are general whole-body movement screens capturing 'dysfunction'? J Strength Cond Res 2015; 29: 3037-3044

[16] Mokkink LB, Terwee CB, Patrick DL et al. The COSMIN checklist for assessing the methodological quality of studies on measurement properties of health status measurement instruments: an international Delphi study. Qual Life Res 2010; 19: 539-549

[17] Stankovic T.Assessing the Interrater Reliability of Goniometric Measurements of a Range-of-motion Battery [Masters thesis]. 2017 Mar; Available from: https://tspace.library.utoronto.ca/ handle/1807/76670

[18] Marras WS, Davis KG, Ferguson SA et al. Spine loading characteristics of patients with low back pain compared with asymptomatic individuals. Spine 2001; 26: 2566-2574

[19] Rothman KJ. No adjustments are needed for multiple comparisons. Epidemiology 1990; 1: 43-46

[20] R Core Team. R: a Language and Environment for Statistical Computing [Internet]. Vienna, Austria: R Foundation for Statistical Computing; 2020. Available from: https://www.R-project.org/

[21] Harriss D], MacSween A, Atkinson G. Ethical standards in sport and exercise science research: 2020 update. Int J Sports Med 2019; 40: 813-817

[22] Noda T, Verscheure S. Individual goniometric measurements correlated with observations of the deep overhead squat. Athl Train Sports Health Care 2009; 1: 114-119

[23] Sprague PA, Mokha GM, Gatens DR et al. The relationship between glenohumeral joint total rotational range of motion and the functional movement screen shoulder mobility test. Int J Sports Phys Ther 2014; 9: 657-664

[24] McCunn R, Aus der Fünten K, Fullagar HHK et al. Reliability and association with injury of movement screens: a critical review. Sports Med 2016; 46: 763-781 
[25] Moran RW, Schneiders AG, Mason J et al. Do functional movement screen (FMS) composite scores predict subsequent injury? A systematic review with meta-analysis. Br J Sports Med 2017; 51: 1661-1669

[26] Dorrel B, Long T, Shaffer $S$ et al. The functional movement screen as a predictor of injury in National Collegiate Athletic Association Division II athletes. J Athl Train 2018; 53: 29-34

[27] Karuc ], Mišigoj-Duraković M, Šarlija M et al. Can injuries be predicted by functional movement screen in adolescents? The application of machine learning. J Strength Cond Res 2021; 35: 910-919

[28] Schweda S, Leyhr D, Krauß I. The functional movement screen as an injury prediction tool for German physical education and exercise science students: a prospective cohort-study. physioscience 2021; 17: 103-112

[29] Everard E, Lyons M, Harrison AJ. An examination of the relationship between the functional movement screen, landing error scoring system, and 3D kinematic data during a drop jump task. J Strength Cond Res 2019. Online ahead of print. doi: 10.1519/ JSC.0000000000003261
[30] Lockie RG, Schultz AB, Jordan CA et al. Can selected functional movement screen assessments be used to identify movement deficiencies that could affect multidirectional speed and jump performance? J Strength Cond Res 2015; 29: 195-205

[31] Parchmann C], McBride JM. Relationship between functional movement screen and athletic performance. J Strength Cond Res 2011; 25: 3378-3384

[32] Bahr R. Why screening tests to predict injury do not work-and probably never will...: a critical review. Br J Sports Med 2016; 50: 776-780

[33] Davids K, Glazier P, Araújo D et al. Movement systems as dynamical systems: the functional role of variability and its implications for sports medicine. Sports Med 2003; 33: 245-260

[34] Brown P. Movement: Functional Movement Systems - Screening, Assessing, Corrective Strategies On Target Publications. J Can Chiropr Assoc 2012; 56: 316. 